\title{
REVIEW
}

\section{What works? A review of evaluated alcohol misuse interventions among Aboriginal Australians}

\section{DENNIS GRAY, ${ }^{1}$ SHERRY SAGGERS, ${ }^{2}$ BROOKE SPUTORE ${ }^{1} \&$ DEIRDRE BOURBON ${ }^{1}$}

\author{
${ }^{1}$ National Drug Research Institute, Curtin University of Technology, Perth, Western \\ Australia $\mathcal{F}^{2}$ School of Community Services and Social Sciences, Edith Cowan University, \\ Perth, Western Australia
}

\begin{abstract}
Aims. To identify which intervention strategies have been effective in reducing excessive consumption of alcohol, and related harm, among some segments of Australia's Aboriginal population. Design. Items dealing with 'alcohol' and 'evaluation' (27) were identified from the comprehensive electronic data base on Aboriginal alcohol and other drug issues, maintained by Australia's National Centre for Research into the Prevention of Drug Abuse. From these were selected all reports (14) dealing specifically with evaluation of particular intervention projects. These zvere grouped and systematically reviewed under the broad categories of treatment, health promotion education, acute interventions and supply reduction. Findings. $A$ broad range of intervention strategies has been employed. However, few systematic evaluations have been undertaken and the methodologies employed have been generally insufficient to allow robust generalization. The impact of most interventions appears limited but, in part, this may be a function of inadequate resourcing and programme support. Conclusions. Despite the limitations of the evaluation reports, several conclusions can be tentatively drawn. It appears there is a need to employ a broader range of treatment models and complementary intervention strategies. Interventions are generally inadequately resourced. There is a suggestion that supply reduction interventions may be effective. Most importantly, there is a pressing need for more rigorous evaluation studies in cooperation with Aboriginal community organizations.
\end{abstract}

\section{Introduction}

Over recent years, various reports have shown that while fewer Aboriginal than non-Aboriginal Australians drink alcohol, those Aboriginal people who do drink are more likely to do so excessively. $^{1-4}$ Several reports also demonstrate the significant contribution this pattern of consump- tion makes to ill-health and social disruption. ${ }^{5-8}$ This paper reviews the few formally evaluated interventions among Aboriginal people with the aim of identifying their potential contribution to the reduction of excessive consumption and related harm.

It should be noted at the outset that evaluation

Correspondence to: Associate Professor Dennis Gray, National Drug Research Institute, Curtin University of Technology, GPO Box U1987, Perth, WA 6845, Australia.

Submitted 7th April 1998; initial review completed 23rd July 1998; final version accepted 16th July 1999. 
of alcohol intervention projects among Aboriginal people is not a simple matter. Among the complex issues to be considered are the broader political context in which evaluation takes place, including issues of self-determination and financial and social accountability, the costs of evaluation, the abilities of both community organizations and government agencies to conduct adequate evaluations and the use of culturally appropriate methods. ${ }^{9,10}$ To these, we must also add the absence of comprehensive longitudinal data for monitoring change, and the methodological difficulty of linking particular interventions with changes in consumption or harm indicators when those indicators are also influenced by a host of other factors. Given these issues, it is perhaps not surprising that so few programmes have been evaluated.

The National Drug Research Institute has the most extensive library on Aboriginal alcohol and other drug issues in Australia. We have also compiled-from numerous sources-a comprehensive, computer-based, key-worded and annotated bibliography on these issues. At the time of writing, the bibliography includes details of 622 books, book chapters, journal articles, technical reports and manuscripts. For the purpose of this review, we searched the bibliography and identified all those items dealing with alcohol (444) and selected from them those involving evaluation (27). Of these, we selected for review all of those which specifically evaluated particular intervention projects (14). The remainder were general items and reference is made to them only where they contain material of direct relevance to the review.

In this review, the evaluations are grouped according to intervention type and include brief summaries of methods and key findings related to process and/or outcome. Reference is also made to our own experiences and those of workers on some of the 284 projects included on our National Data Base on Aboriginal and Torres Strait Islander Alcohol and Other Drug Projects. ${ }^{11}$

\section{Treatment}

Since the 1970 s, treatment has been the most common form of intervention, and the Office for Aboriginal and Torres Strait Islander Health acknowledges a continuing bias towards this type of intervention in the Commonwealth government's current funding programme. ${ }^{12}$ On our
Data Base on Aboriginal and Torres Strait Islander Alcohol and Other Drug Projects, we identified 79 treatment services specifically for Aboriginal clients. A wide range of counselling options - in both residential and community settings-forms the basis of all these projects, but the majority are based on Alcoholics Anonymous or abstinence principles.

An evaluation of treatment/rehabilitation services provided by 14 Aboriginal organizations was conducted by O'Connor and Associates for the Western Australian Alcohol and Drug Authority in $1988 .{ }^{13}$ It was based on semi-structured interviews with programme staff and collection of statistical data on work-loads and client characteristics. They found that few clients achieved the goal of continuing abstinence. Importantly, however, programmes that included residential facilities or 'dry camps' gave clients 'time out' from drinking, enabling them to improve their health status. The impact of all programmes was limited to a greater or lesser degree by administrative problems and lack of staff expertise.

d'Abbs evaluated three programmes-two residential and one non-residential-and a community-based field worker programme conducted by the Council for Aboriginal Alcohol Program Services in the Northern Territory. ${ }^{14}$ It was based upon a review of documentary data, programme records and comparisons of the drinking status of ex-clients and samples of community members. He identified needs for improved record keeping systems and for governments to ensure adequate and regular funding. He found:

a suggestion that attendance at [one family orientated programme] has modest but real effects on drinking behaviour ... (p. 5).

However, outcomes at other locations were equivocal, and he concluded that the effectiveness of all services was limited because they were based on a narrow range of treatment options. $\mathrm{He}$ also concluded that '... community-based field workers constitute an essential complement to residential programmes' (p. 7).

Results of an evaluation of the Central Australian Aboriginal Alcohol Programs Unit's (CAAAPU) residential programme, undertaken by Miller $\&$ Rowse, was similarly equivocal..$^{15}$ They conducted a review of client registration 
and discharge forms, conducted interviews with staff and residents and followed-up 25 ex-clients. They found that there were no agreed criteria against which success could be measured andeven if there had been such criteria-CAAAPU was inadequately funded to obtain necessary follow-up data on ex-clients. The evaluation identified problems in the administration of CAAAPU which, in part, led to its subsequent closure. However, it has since re-opened.

\section{Health promotion}

After treatment, health promotion programmes have been the most common intervention. Some of these are based on the assumption that people misuse alcohol because they simply lack knowledge, others aim at changing specific drinking behaviours. Evaluations of these have focused on either programme processes or short-term outcomes, rather than longer-term impact on consumption patterns and related harm.

In Victoria, the Koori Alcohol and Drug Prevention Project was initiated in 1985. It began with a broad set of treatment and prevention objectives to be implemented by Aboriginal alcohol and drug workers in four regional locations. However, due to a change in funding arrangements, the project was required to limit its focus to the provision of health promotion services-including education classes, sporting and recreational activities, and support for homeless people. Evaluation of the project was based on un-structured and semi-structured interviews with staff, clients and community members. ${ }^{16}$ It focused upon describing the services, impediments to their delivery and their acceptance by the community. The evaluators found that, although the services were well received, they were compromised by lack of support structures for the alcohol and drug workers. Alsobecause Aboriginal people did not generally use mainstream services-considerable pressure was placed on the alcohol and drug workers to provide a wider range of services (including counselling) for which funding was not provided.

In 1993, the Commonwealth government funded a campaign in the Northern Territory targeting Aboriginal adolescent alcohol abuse. It consisted of a bush tour by the Aboriginal band Yothu Yindi and an associated television commercial. It was evaluated by Milne et al. on the basis of qualitative data on perceptions of the impact of, and response to, the campaign message, and quantitative data on exposure. ${ }^{17}$ They claimed that the tour was effective in reaching the target group in those communities visited, and highlighted existing anti-alcohol abuse agendas, although people's perceptions about the probable impact of the message were mixed. Exposure to the television commercial varied depending upon local viewing habits; responses to it were generally positive, but interpretations of its message varied. Importantly, Aboriginal health workers and teachers expressed a need for supporting information and project material. However, the campaign was the subject of some criticism in a report prepared for the Central Australian Aboriginal Congress by Maher \& Tilton. ${ }^{18}$ This argued that the campaign was compromised by its 'top-down' approach, and the fact that while some Aboriginal groups in the 'top-end' of the Northern Territory were consulted, those in Central Australia were not, and as a consequence it was culturally inappropriate for people living in the latter area.

In the same year (1993), the Queensland Department of Education, in cooperation with an Aboriginal community, developed a schoolbased alcohol education package called 'When you think about it'. It focused on issues such as drink driving and the disruptive effects of excessive consumption. Attempts at quantitative evaluation were thwarted by high absentee rates and small numbers of students completing pre- and post-intervention questionnaires..$^{19}$ On the basis of qualitative data, the evaluators concluded that while students responded positively to the locally developed package:

The effect of the teaching programme on the student's attitudes and beliefs seemed limited which is not surprising given the already strong anti-alcohol attitudes of the sample group (p. 217).

They concluded that, in implementing such projects, there is a need for in-service training of teachers focusing on informal group work, group exercises and activities, role-play, community involvement and community based promotion.

A local drug education programme for Aboriginal children aged 9-16 years was also developed on Palm Island in Queensland. Based on social learning principles this programme sought to help children identify the reasons for alcohol 
consumption, the physiological and social effects of harmful use and peer pressures to drink, and to provide them with enhanced self-esteem and skills to resist pressures to drink. The evaluation included pre- and post-intervention surveys of participants $(n=26)$ and a control group $(n=38){ }^{20}$ Students were found to have responded positively to the content and methods of programme delivery, and the questionnaire data suggested '.. that the programmeme succeeded in making the children more aware of the influence of peer pressure'. The evaluators also claimed that:

... there is some evidence that the programme may have caused fewer children to take up drinking than otherwise would have been expected (p. 37).

However, they urged that the finding be treated cautiously.

Recently, we assisted staff from the Karalundi Aboriginal Education Centre in Western Australia to evaluate a similar small-scale programme. ${ }^{21}$ The programme was designed to be evaluated using qualitative data and pre- and post-intervention questionnaires to be administered to participants and a control group in a neighbouring community. The former provided some indications of limited positive changes in knowledge and behaviour. However, the evaluation as a whole was compromised by methodological difficulties stemming from the lack of expertise on the part of programme staff, and lack of support for them. It did, however, raise a resourcing issue with important implications. Although the community received project grants of $\$ 17300$, implementation of the programme cost an additional $\$ 32000$ in donations of time and resources!

\section{Acute interventions}

In the past decade, Aboriginal organizations have developed a number of 'acute interventions' aimed at reducing the immediate harm associated with excessive drinking. These include night patrols, sobering-up shelters and personal injury prevention initiatives. Of these, only sobering-up shelters have been subject to any evaluation. The impetus for the establishment of sobering-up shelters came with the decriminalization of public drunkenness in various jurisdictions. There are now over 24 of them in diverse locations throughout the country. Their aim is to provide a temporary haven for, and supervision of, intoxicated people at risk of causing harm to themselves or others. Importantly, they provide a more appropriate alternative to placing intoxicated people in police custody, and the Royal Commission into Aboriginal Deaths in Custody urged the establishment of more shelters as one of many strategies for reducing such deaths. ${ }^{8}$

Daly \& Gvozdenovic attempted to elicit attitudes to the decriminalization of public drunkenness and the establishment of sobering-up shelters through the conduct of unstructured interviews with an unspecified number of Aboriginal people, police and others. ${ }^{22}$ The study was conducted in three towns in Western Australia that had established sobering-up shelters and one that did not. They found that the shelters had generally been well accepted by both clients and the police (who reported that diversion of apprehended people to shelters reduced their administrative work-load).

While this has been the only focused evaluation of sobering-up shelters, other reports provide information relevant to judgements about their effectiveness. As indicated, a prime objective has been diversion of intoxicated people from police lock-ups. An early report by $\mathrm{Mc}$ Donald on the operation of sobering-up shelters in Darwin and Tennant Creek found that $60 \%$ of intoxicated people detained by police were diverted to them. ${ }^{23}$ In Halls Creek, Western Australia, in the first 15 months of its operation $78 \%$ of people detained for public drunkenness were diverted to the sobering-up shelter. ${ }^{24}$

McDonald also noted that provision of sobering-up shelters was not cheap. ${ }^{23}$ Subsequently, Alexander reported that in 1985-86 the mean cost per admission at the Darwin shelter was $\$ 94$ and at Tennant Creek was $\$ 146$ (because of similar basic costs but fewer admissions). ${ }^{25}$ In its first 6 months of operation the mean cost at Alice Springs was $\$ 74$. This compared with prison costs of between $\$ 82$ and $\$ 93$ per day in NT prisons and hospital bed day costs of between $\$ 290$ and $\$ 350$. Sobering-up shelter costs appeared greater than the cost of detaining prisoners in police cells-estimated at $\$ 50$ per daybut the costs were not directly comparable because the latter did not include cell staffing costs. Although the cost of detaining people in sobering-up shelters appeared to be higher than 
detaining them in police cells, Alexander argued that the shelters provided a number of qualitative gains including more comfortable and dignified treatment and, for a small number, entry to other services. Midford, Daly \& Holmes and Daly \& Maisey also reported that the establishment of sobering-up shelters in Halls Creek and other areas in Western Australia has been a catalyst to further local actions to address alcohol misuse and associated harm. ${ }^{24,26}$

\section{Supply reduction}

Supply reduction is not a new strategy for reducing alcohol consumption among Aboriginal people. From the early 1800 s through to the 1970 s various Australian colonial and state/territory governments sought to prohibit the supply of alcohol to Aboriginal people. This was only partially successful and--as part of moves to grant equal rights to Aboriginal people--was abandoned. Nevertheless, in recent years, various Aboriginal community organizations have called for the re-imposition of prohibitions or other supply reduction measures at the local level.

In response to calls from some Aboriginal communities for total prohibition, and attempts by non-Aboriginal people to force Aboriginal people from drinking in public places, some governments have passed legislation enabling the declaration of 'dry' or restricted areas. ${ }^{27}$ This legislation varies between jurisdictions and its impact has only been evaluated in the Northern Territory-where communities can apply for restricted area status under provisions of the Liquor Act. The evaluation, by d'Abbs, was based on documentary sources, official statistics and informal interviews and included four case studies on the effect of 'dry' status. ${ }^{28} \mathrm{He}$ concluded that:

... the restricted areas provisions should be adjudged a qualified success. They are a success insofar as they are shown to have been accompanied by an improvement in the 'quality of life' in several communities. The success is qualified on at least two counts: firstly, the beneficial effects of dry area status are not to be found in all dry areas; secondly, some of the procedures used in the declaration and enforcement of dry area provisions are cumbersome and/or inefficient, while others smack so much of a heavy-handed prohibitionist stance that they do little to foster responsible com- munity control over alcohol consumption (p. 7).

He went on to say that the provisions themselves did not guarantee community control over alcohol. For this to be achieved, communities need to have a coherent strategy for dealing with alcohol, restrictions must have community support and there must be clearly agreed roles for controlling liquor consumption on a day-to-day basis.

These latter concerns were echoed by Hedges \& McCallum, both of whom conducted reviews of the Western Australian Aboriginal Communities Act (1979)-which includes provisions for communities to declare themselves dry. ${ }^{29,30} \mathrm{McCal}-$ lum reported that although the Act made provision for communities to enforce their dry area status, such provision was later found to be invalid and enforcement remained the domain of the police. As the police have no permanent presence in the communities and as the communities are not able to enforce the by-laws independently of them ' $\ldots$ alcohol continues to flow more or less freely'.

In November 1992, in Halls Creek, restrictions were imposed on licensees which prohibited take-away sales before 12.00 p.m., restricted sales of cask wine to the hours between 4.00 and 6.00 p.m., and limited cask wine sales to one cask per person per day. The restrictions were evaluated by Douglas, who compared levels of alcohol consumption and crime and health indicators prior and subsequent to the introduction of the restrictions. ${ }^{31} \mathrm{He}$ found that the restrictions led to a reduction in wine consumption of $39 \%$ and a reduction in overall alcohol consumption of $7.5 \%$; but that it was not possible to link this directly to a decline in other indicators.

In 1995, the Northern Territory Liquor Commission agreed to a trial of alcohol restrictions for a period of 6 months in the town of Tennant Creek. The trial was conducted in two 13-week phases. Combinations of restrictions in each phase varied, but included restrictions on: Thursday trading (the day on which social security payments were made); the hours in which takeaways could be sold; front bar trading; and cask wine sales. The evaluation included comparison of law and order, health and welfare and economic indicators during the trial period with those for the corresponding period in the previous year. ${ }^{32}$ These showed that the trial had 
resulted in reduced police incidents and disturbances to public order, and fewer alcohol-related hospital presentations and admissions to the women's refuge. A downturn in alcohol sales in the town itself was offset partly by increases in sales at roadside inns and, while wine sales fell, purchases of full-strength beer increased. Nevertheless, there was reported to be a $2.7 \%$ reduction in total consumption.

Consequently, the Liquor Commission amended the licenses of hotels and takeaway outlets in Tennant Creek to include: a ban on sales of wine in casks of $>2$ litres; closure of front bars on Thursdays; and other restrictions on both takeaway and bar trading hours. Gray $e t$ al. evaluated these based on the methods of d'Abbs et al. ${ }^{33}$ For the 12 months prior, and the 24 months subsequent, to introduction of the restrictions, they compared alcohol consumption, hospital admissions for alcohol-related diagnostic groups, police detentions and offences and other indicators. They also conducted a random sample survey of residents $(n=271)$ on attitudes towards the restrictions. Over a 2-year period, per capita consumption decreased by $19.4 \%$ (although it still remained twice the national average); there were significant declines in admissions for acute alcohol-related conditions; and the proportion of offences committed on Thursdays declined. Furthermore, all of the restrictions were supported by a majority of both Aboriginal and non-Aboriginal residents.

In 1997, d'Abbs \& Togni conducted an evaluation of restrictions on alcohol availability in Derby, Western Australia. ${ }^{34}$ The restrictions were part of a voluntary 'accord' between licensees and the Derby Alcohol Action Group, reached after similar restrictions imposed by the Director of Liquor Licensing were declared invalid by the Licensing Court. They included: no sales of packaged liquor on Thursdays; restriction of packaged liquor sales on other days to the hours of 12.00-10.00 p.m.; and no sales of 4litre casks of wine. It was found that the trial may have resulted in a small fall in alcohol consumption $(0.2 \%)$, but this may also have been part of a pre-existing trend. There was drop of $37 \%$ in the incidence of assaults, sexual offences, damage and threatening behaviour. However, there was insufficient evidence to indicate whether there had been reductions in other harm indicators. Responses to the measures were mixed, but among members of the Aboriginal community:
There appears ... to be a widespread belief that the problems associated with alcoholmisuse are too pervasive, and too complex, to be adequately addressed by imposed restrictions (p. 11) (Table 1).

\section{Discussion}

Clearly, on the basis of so few formal evaluations, any conclusions about what works can only be tentative. Too few intervention programmes have been evaluated and the methodologies involved in some of those that have-particularly those of treatment and health promotion programmes-are not sufficiently robust to allow generalization. Nevertheless, there are lessons to be learnt from the studies reviewed-some of these relate to specific intervention types and others are of more general application.

The three evaluations which covered some 18 treatment programmes were either inconclusive or suggested only modest gains. ${ }^{13-15}$ Given both inter- and intracommunity diversity, the narrow range of treatment models-identified by d'Abbs and on our National Data Base on Aboriginal and Torres Strait Islander Alcohol and other Drug Projects-is probably one limiting factor in this. ${ }^{11,14}$ Given this, there have been calls for broadening the range of treatment objectives and strategies. ${ }^{35}$ Controlled drinking has been advocated as an alternative to abstinence. However, this has been resisted by representatives of many Aboriginal organizations who argue that it is not a realistic option in communities where heavy drinking is endemic. Also, given the high cost of the apparently slight gains from residential treatment programmes, there have been calls for the trialling of brief intervention strategies. Although the feasibility of conducting a trial at Alice Springs has been explored, to date there have been no evaluations of brief interventions among Aboriginal people. ${ }^{36}$

As with treatment programmes, those health promotional programmes that have been evaluated have not yielded impressive results. ${ }^{16-21}$ Again, this may be due in part to a lack of robustness in the methodologies employed. However, the limited efficacy of such programmes in other populations-especially when conducted in isolation-should be borne in mind. ${ }^{37}$ Sobering-up shelters have been shown to be an acceptable intervention strategy to both 


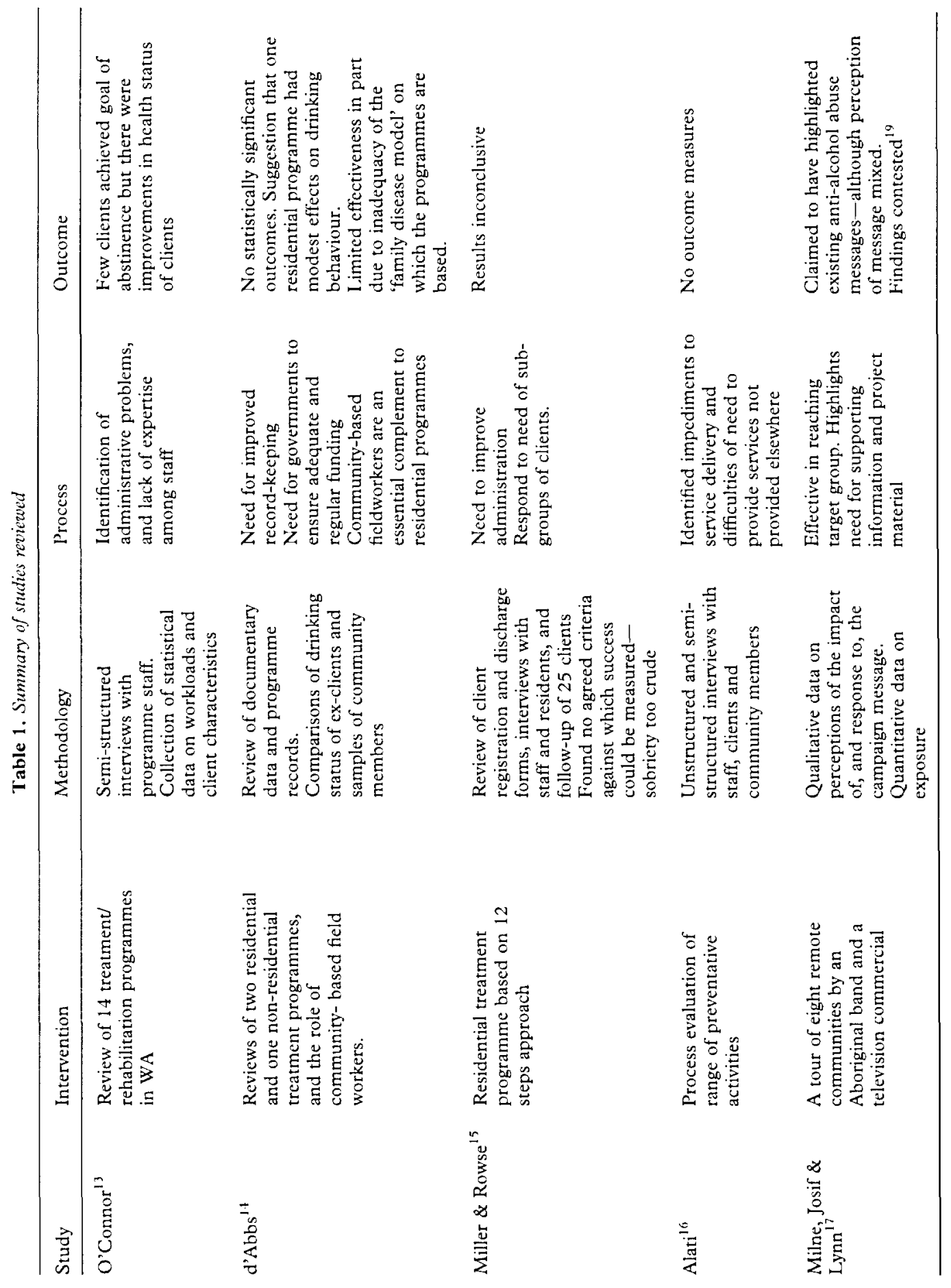




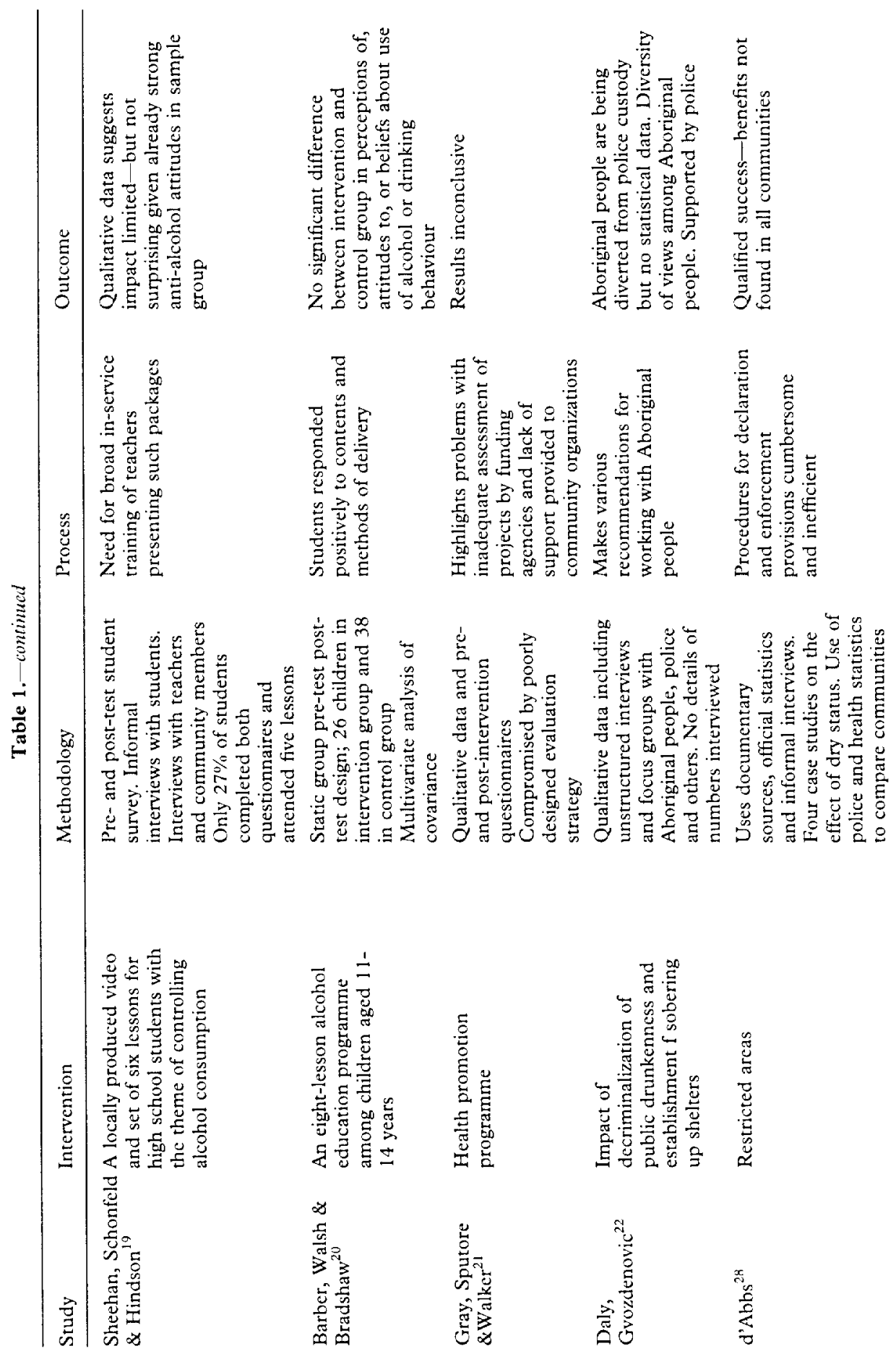



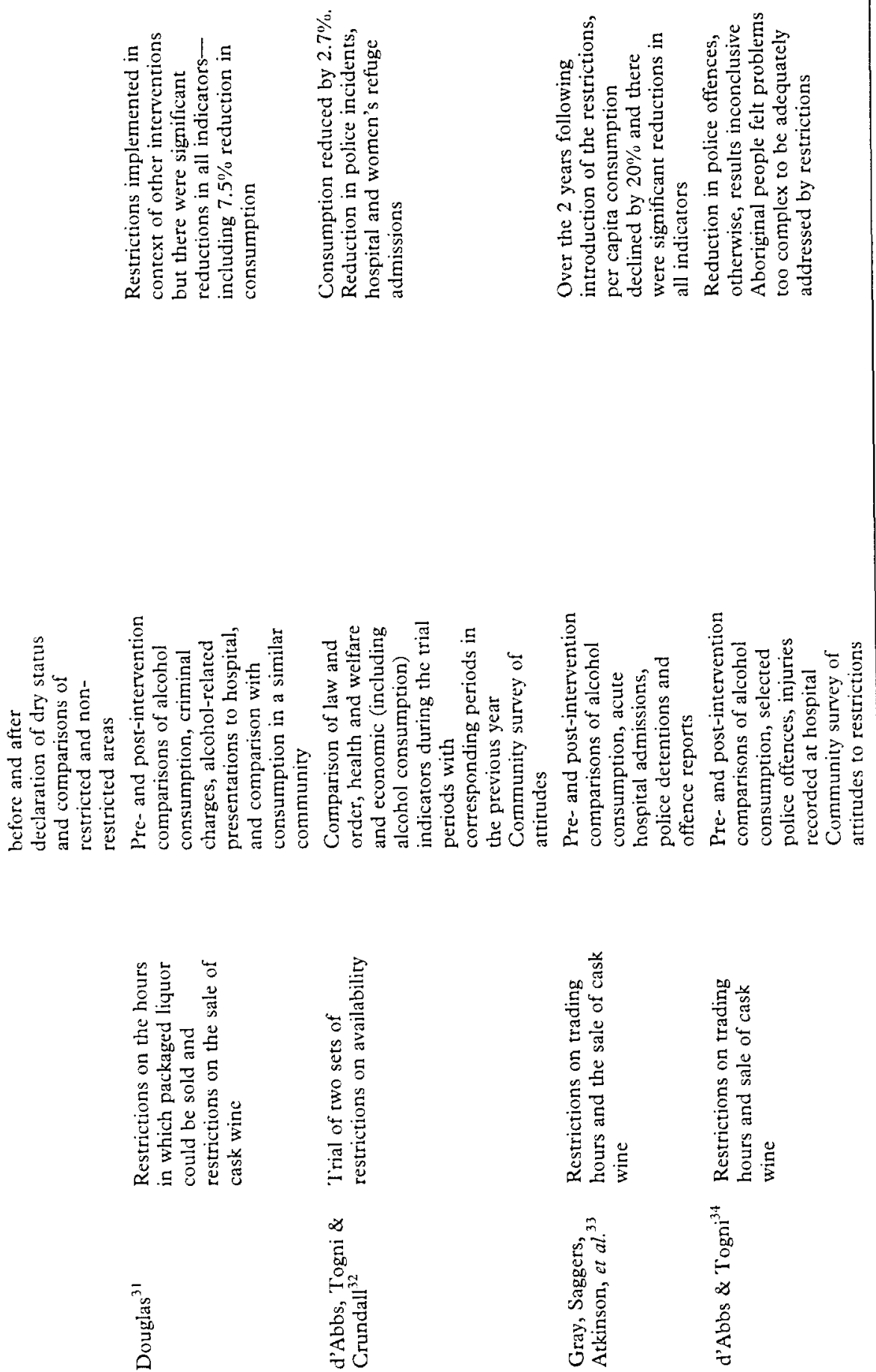
community members and police, and there is evidence that they provide a cost-effective means of diverting intoxicated people from police lock ups. ${ }^{22-26}$ As yet, however, there is no quantitative evidence of their impact on indicators of alcoholrelated harm.

Of those interventions evaluated, restrictions on the supply of alcohol appear to have produced the most tangible results. ${ }^{31-34}$ This may be because the results are more easily demonstrable. Nevertheless, even here the evaluation reports show considerable variation in the effect and the authors of all these reports emphasize that, alone, restrictions are not likely to provide any longterm solution. Certainly, however, restrictions on cask wine have played a significant part in their success. Cask wine has been a particular focus of restrictions because of its low cost per standard drink-a function of economies of scale in production and resulting low wholesale tax imposition. In all instances where its sale has been restricted or, in the Northern Territory, when an additional levy of $\$ 0.35$ per litre was imposed on its wholesale price, there has been substitution of other beverages. However, because of the price differential, this substitution has not resulted in total replacement and has led to a reduction in total alcohol consumption. ${ }^{38,39}$

Importantly, all three treatment evaluations showed that, at least in part, the effectiveness of the programmes was circumscribed by administrative deficiencies and/or lack of staff expertise. ${ }^{13-15}$ Similarly, the evaluations of four of the health promotion programmes highlighted the need for greater staff support and the provision of supporting educational resources. ${ }^{16,17,19,21}$ These factors themselves are likely to be related to the inadequate and uncertain provision of funding by government agencies highlighted by d'Abbs and Gray et al. ${ }^{14,21}$

d'Abbs' identification of community-based fieldworkers as an 'essential' part of residential treatment programmes has both specific and general implications. On one hand it highlights the lack of after-care which representatives of many Aboriginal treatment agencies have identified as a significant impediment to the effectiveness of their programmes. More broadly, it highlights the synergistic effects that interventions can have upon each other. This is reflected in those reports which indicated that sobering-up shelters were either a point of entry into other programmes or a catalyst to other community action. ${ }^{24-26}$
These few studies suggest that-as among other populations - there is no simple solution to the problem of excessive alcohol consumption among Aboriginal people. The gains from any particular intervention are likely to be limited, but can be enhanced when they form part of a broader intervention strategy. Indeed-although it has yet to be evaluated-this is the approach taken in the Northern Territory's 'Living with Alcohol' programme. ${ }^{40}$ The studies also suggest that the effectiveness of programmes can be compromised by inadequate resourcing. This underlines the view that transfer of service delivery to community-controlled organizations should be undertaken with the objective of ensuring appropriateness and accessibility of servicesnot as a cost-cutting exercise. ${ }^{9}$ The review also highlights the need for more evaluative studies of Aboriginal intervention programmes. Again, however, this needs to be carried out cooperatively with Aboriginal community organizations with the objective of improving service delivery and not as a means of exercising bureaucratic control.

Focus on effective alcohol intervention programmes should not lead us to ignore the broader context in which Aboriginal drinking takes place. While by no means the only reason for excessive drinking among them, Saggers \& Gray have argued that the elevated rates to be found among indigenous peoples are attributable to political and economic inequalities stemming from colonialism and dispossession. ${ }^{41}$ Attention to enhanced, well-resourced and coordinated intervention programmes does have the potential to make significant inroads into excessive drinking and related harm among Aboriginal people. However, in the interests of both greater public health gains and social justice, there is a need to redress the fundamental inequalities faced by Aboriginal people.

\section{Acknowledgements}

Research for this paper was supported by the National Drug Research Institute, Curtin University of Technology and the School of Community Services and Social Sciences, Edith Cowan University. The National Drug Research Institute is funded as part of Australia's National Drug Strategy. 


\section{References}

1. Alstralia, Department of Health and FamILY SERvices (1995) National Drug Strategy Household Survey: urban Aboriginal and Torres Strait Islander supplement 1994 (Canberra, Australian Government Publishing Service).

2. Hunter, E., Hall, W. \& Spargo, R. (1992) Patterns of alcohol consumption in the Kimberley Aboriginal population, Medical foumal of Australia, 156, 764-768.

3. Perkins, J.J., Sanson-Fisher, R.W., Bllnden, S., Llnjay, D., Redman, S. \& Hensley, M.J. (1994) The prevalence of drug use in urban Aboriginal communities, Addiction, 89, 1319 1331 .

4. Watson, C., Fleming, J. \& Alexander, K. (1988) A Survey of Drug Use Patterns in Northern Territory Aboriginal Communities: 1986-1987 (Darwin, Northern Territory Department of Health and Community Services).

5. Gray, A. (1990) A Matter of Life and Death: contemporary Aboriginal mortality (Canberra, Aboriginal Studies Press).

6. UnWIN, E., Thomson, N. \& Gracey, M. (1994) The Impact of Tobacco Smoking and Alcohol Consumption on Aboriginal Mortality and Hospitalisation in Westem Australia: 1983-1991 (Perth, Health Department of Western Australia).

7. Weeramanthri, T., D'AbBs, P. \& Mathews, J. (1994) Towards a definition of an alcohol-related death: an analysis in Aboriginal adults, Australian Fournal of Public Health, 18, 71-78.

8. Australia, Royal Commission into AborigiNal. Deaths in Custody (Johnson E, Commissioner) (1991) Royal Commission into Aboriginal Deaths in Custody: national report, 4 vols (Canberra, Australian Government Publishing Service).

9. Gray, D., Saggers, S., Drandich, M., WatLAM, D. \& Plowright, P. (1995) Evaluating government health and substance abuse programmes for indigenous peoples: a comparative review, Australian foumal of Public Health, 19, $567-572$

10. Gray, D. \& Sputore, B. (1998) The effective and culturally appropriate evaluation of Aboriginal communiry alcohol intervention projects, in: STockwell, T. (Ed.) Drug Trials and Tribulations: lessons for Australian policy, pp. 37-51 (Perth, National Centre for Research into the Prevention of Drug Abuse).

11. MorfitT-Sputore, B., Gray, D., Richardson, C. \& Exon M. (1997) National Data Base on Aboriginal and Torres Strait Islander Alcohol and Other Drug Projects [for IBM compatible personal computers, includes six discs and user manual] (Perth, National Centre for Research into the Prevention of Drug Abuse, Curtin University of Technology).

12. Australia, OFFice for Aborignal and Torres Strait Islander Health Services, DepartMENT OF Health AND Family SERVICES (1998) Review of the Commonwealth's Aboriginal and Torres Strait Islander Substance Misuse Programmeme: interim report to stakeholders (Canberra, Department of Health and Family Services).

13. O'Connor, R. \& Associates PTY LTD (1988) Report on the Aboriginal alcohol treatment/rehabilitation programmes review and consultation, typescript (Perth, Western Australian Alcohol and Drug Authority).

14. D'ABBS, P. (1990) Responding to Aboriginal Substance Misuse: a review of programmes conducted by the Council for Aboriginal Alcohol Programme Services (CAAPS), Northem Territory (Darwin, Northern Territory Drug and Alcohol Bureau, Department of Health and Community Services \& Aboriginal and Torres Strait Islander Commission).

15. MILLER, K. \& Rowse, T. (1995) CAAAPU (Central Australian Aboriginal Alcohol Programmes Unit): an evaluation, Menzies occasional papers issue no. 1/95 (Darwin, Menzies School of Health Research).

16. Alati, R. (1993) Evaluation of the Koori Alcohol and Drug Prevention Project: final repon (Melbourne, Koori Health Unit, Victorian Department of Health and Community Services).

17. MLLNe, C., Josif, P. \& LYNN, D. (1993) Raypirri: evaluation of the Northern Territory Bush Tour Project, April-June 1993 (Canberra, Public Affairs Branch, Commonwealth Department of Health, Housing, Local Government and Community Services).

18. Maher, C. \& Tilton, E. (1994) Health Promotion or Self-Promotion? A Central Australian alcohol media strategy (Alice Springs, Central Australian Aboriginal Congress).

19. Sheman, M., Schonfeld, C., Hindson, E. \& BALlARD, R. (1995) Alcohol education in an indigenous community school in Queensland, Australia, Drugs: Education, Prevention and Policy, 2, 259-273.

20. Barber, J.G., Walsh, C. \& Bradshaw, R. (1989) Alcohol Education for Aboriginal Children, National Campaign Against Drug Abuse Monograph Series no. 10 (Canberra, Australian Government Publishing Service).

21. Gray, D., Sputore, B. \& Walker, J. (1998) Evaluation of an Aboriginal health promotion programme: a case study from Karalundi, Health Promotion foumal of Australia, 8, 24-28.

22. DALY, A. \& Gvozdenovic, A. (1994) Evaluation of the Impacts of Public Drunkenness Decriminalisation Legislation and the Establishment of Sobering Up Facilities on Aboriginal People in Northem Westem Australia, 2 vols (Perth, Western Australian Alcohol and Drug Authority).

23. MCDONALD, D.N. (1985) Sobering-up shelters for people found intoxicated in public places: the Northern Territory experience, typescript, $12 \mathrm{pp}$. (Darwin, Drug and Alcohol Bureau, Northern Territory Department of Health).

24. Midford, R., Daly, A. \& Holmes, M. (1994) The care of public drunks in Halls Creek: a model for community involvement, Health Promotion foumal of Australia, 4, 5-8.

25. AlexandeR, K. (1988) Data on the operation of NT sobering-up shelters, typescript, 8 pp. (Dar- 
win, Drug and Alcohol Bureau, Northern Territory Department of Health).

26. Daly, A. \& Maisey, G. (1993) Police Officers' Perceptions of Decriminalisation of Public Drunkenness and Sobering Up Centres in Western Australia (Perth, Western Australian Alcohol and Drug Authority).

27. D'ABвs, P. (1990) Restricted areas and Aboriginal drinking, in: VervoN, J. (Ed.) Alcohol and Crinte: proceedings of a conference held 4-6 April 1989 (Canberra, Australian Institute of Criminology).

28. D'A BBs, P. (1990) Dry Areas, Alcohol and Aboriginal Communities: a review of the Nonhem Territory restricted areas legislation (Darwin, Drug and Alcohol Bureau, Northern Territory Department of Health and Community Services \& Racing, Gaming and Liquor Commission).

29. Hedges, J.B. (1986) Community Fustice Systems and Alcohol Control: recommendations relating to the Aboriginal Communities Act and dry area legislation in Western Australia (Perth, Aboriginal Affairs Planning Authority).

30. MCCallum, A. (1992) Review of the Aboriginal Communities Act, 1979 (WA), 2 vols (Perth, Aboriginal Affairs Planning Authority).

31. Douglas, M. (1998) Restrictions of the hours of sale in a small community: a beneficial impact, Australian and New Zealand foumal of Public Health, 22, 714-719.

32. D'Abis, P., Togni, S. \& Crundall, I. (1996) The Tennant Creek Liquor Licensing Trial, August 1995-February 1996: an evaluation, Menzies occasional papers issue no. 2/96 (Darwin, Menzies School of Health Research \& Northern Territory Living With Alcohol Programme).

33. Gray, D., Saggers, S., Atkinson, D. et al. (1998) Evaluation of the Tennant Creek Liquor Licensing Restrictions: a report prepared for the Tennant Creek Beat the Grog Sub-Committee (Perth,
National Centre for Research into the Prevention of Drug Abuse).

34. D'AbBs, P. \& Togn, S. (1997) The Derby Liquor Licensing Trial: a report on the impact of restrictions on licensing conditions between 12 fanuary 1997 and 12 fuly 1997 (Darwin, Menzies School of Health Research).

35. BRady, M. (1995) Broadening the Base of Interventions for Aboriginal People with Alcohol Problems, National Drug and Alcohol Research Centre technical report no. 29 (Sydney, National Drug and Alcohol Research Centre).

36. Watson, C., Borger, M., Peterkin, R. \& TYRreld, S. (1990) Alcohol Intervention in Alice Springs Hospital-what's possible?: an evaluation of a two week trial (Alice Springs, Northern Territory Department of Health and Community Services).

37. Edwards, G., Anderson, P., Babor, T.F. et al. (1994) Alcohol Policy and the Public Good (Oxford, Oxford University Press)

38. Gray, D., Chikritzhs, T. \& Stockwell T. (1999) The Northem Territory's cask wine levy: health and taxation policy implications, Australian and New Zealand Foumal of Public Health, $23,87-89$.

39. GRAY, D. \& ChIKRITZHS, T. (1999) Regional variation in alcohol consumption in the northern territory, Australian and New Zealand foumal of Public Health, in press.

40. CrundalL, I. (1994) The Northem Territory Living With Alcohol Programme: progress to fuly 1993 (Darwin, Alcohol and Other Drugs Programme, Northern Territory Department of Health and Community Services).

41. SAGgers, S. \& GRAY, D. (1998) Dealing with Alcohol: indigenous usage in Australia, New Zealand and Canada (Melbourne, Cambridge University Press). 